\title{
Characterization of Extended Spectrum $\beta$-Lactamase Producing Bacteria Isolated from Urinary Tract Infections
}

\author{
Sultana $\mathrm{M}^{1}$, Sultana $\mathrm{KF}^{1,3}$, Mukharje $\mathrm{SK}^{1,3}$, Parvez MAK ${ }^{2}$, Hossain $\mathrm{MA}^{1 *}$ \\ ${ }^{1}$ Department of Microbiology, University of Dhaka, Dhaka, Bangladesh; ${ }^{2}$ Department of \\ Microbiology, Jahangirnagar University, Dhaka, Bangladesh; ${ }^{3}$ Department of Microbiology, \\ Noakhali Science and Technology University, Noakhali, Bangladesh
}

\begin{abstract}
Background: A unique challenge for clinical microbiologists, clinicians, infection control professionals is to deal with extended-spectrum $\beta$-lactamase (ESBL) producing pathogens.

Objectives: The study was aims to isolate ESBL producing bacteria from urine samples of Urinary Tract Infection (UTI)-patients and to analyses their phenotypic and genotypic characteristics.

Methods: A total of 90 urine samples from UTI patients were collected from Enam Medical College Hospital and Gonoshastha Medical College Hospital, Savar, Dhaka, Bangladesh; between May-2012 to August-2012. A total 75gram negative isolates were retrieved and screened for ESBL production by the Double Disk Diffusion Synergy Test (DDST). Isolates with ESBL phenotype were further characterised by antibiotic susceptibility testing, PCR and sequencing of $\beta$-lactamase genes.

Results: Cultural and biochemical assay combined with 16S rRNA gene based phylogenetic identification confirmed that Escherichia spp. were predominant pathogens associate with UTI (41\%), and the rest were distributed within the genus Enterobacter spp. 26\%, Klebsiella spp. 21\%, and Pseudomonas spp.10\%. Total 31 isolates were phenotypically confirmed as ESBLs through DDST. The multidrug resistant (MDR) and ESBL producing bacteria showed high resistance to cefotaxime (96\%), cefixime (90\%) and imipenem (32\%). PCR reaction was carried out targeting the genes bla $a_{\mathrm{TEM}}$, bla $a_{\mathrm{CTX}}$. Dominant ESBL class was CTX-M (65\%) followed by TEM (52\%). All ESBL isolates except 7 possesses multiple plasmids indicating possibility of both chromosomal and plasmid inheritance of ESBLs.

Conclusions: This study shows a high prevalence of ESBL producing MDR in UTI patients among these two hospitals of Bangladesh indicating the necessity of alternative therapeutic intervention.
\end{abstract}

Keywords: Extended-spectrum $\beta$-lactamase, CTX-M type, Double disk diffusion synergy test, MDR

\section{Introduction}

Antibiotics of $\beta$-lactam group have been most widely used in infection management due to its effectiveness on a broad range of microorganisms. In Bangladesh, $\beta$-lactam antibiotics are frequently used drugs and are often sold without a physician's prescription. ${ }^{1}$

This indiscriminate and inappropriate use of antibiotics results alarming situation like the

*Correspondence: M Anwar Hossain, Department of Microbiology,

University of Dhaka, Dhaka, Bangladesh;

e-mail: hossaina@du.ac.bd progressive loss of susceptibility towards $\beta$-lactam antibiotics in the treatment of a wide range of clinical conditions. ${ }^{2-4}$ The production of $\beta$ lactamases is an important mechanism of resistance to $\beta$-lactam antibiotics especially in gram negative bacteria. From many years, extended-spectrum $\beta$ lactamases (ESBLs) have been contributing to the dramatic increase in resistance to new generation $\beta$-lactam agents throughout the world. ${ }^{5-7}$

Urinary tract infections (UTIs) have been reported to affect up to 150 million individuals annually worldwide. ${ }^{8}$ Escherichia coli are the most common cause of UTIs in women and because of its high 
incidence, have been studied during numerous epidemiological studies. ${ }^{9}$ UTIs are commonly found in adult women and reports of high incidents of community acquired UTIs are available from Asia Pacific, Denmark, Japan, India, Russia, and the USA. ${ }^{10-12}$

According to the proposal by European Centre for Disease Prevention and Control (ECDC) and the Centers for Disease Control and Prevention (CDC), multidrug-resistant (MDR) is defined as nonsusceptibility to at least one agent in three or more antimicrobial categories; otherwise extensively drug-resistant (XDR) is defined as non-susceptibility to at least one agent in all but two or fewer antimicrobial categories (i.e. bacterial isolates remain susceptible to only one or two categories). Pandrug-resistant (PDR) is defined as nonsusceptibility to all agents in all antimicrobial categories (i.e. no agents tested as susceptible for that organism). ${ }^{13}$ In Bangladesh, UTI is both community and hospital acquired. The emergence of MDR strains in UTI patients from earlier of this decade has imposed a threat of epidemiology all over the world. ${ }^{14-16}$ Treatment of UTIs varies according to the age of the patient, sex, underlying disease, infecting agent and whether there is lower or upper urinary tract involvement. ${ }^{17}$

ESBL-producing organisms are frequently associated with UTIs. ${ }^{18}$ The emergence of ESBL producing organisms including Enterobacteriaceae in UTI patient causes problem in treatment which may result serious obstacles. In Bangladesh, high percentage of ESBL strains from common Gramnegative urinary pathogens along with MDR and transferable drug resistance properties have been isolated from UTI patients. ${ }^{19-21}$ Despite few reports in the presence of ESBLs in UTI patients of Bangladesh, their genotypic trait is still unknown and there is still need of comprehensive characterization of ESBL genotypes of UTI origin in Bangladesh. Therefore, the present study was undertaken to determine the prevalence, molecular characteristics and phylogenetic correlations of ESBLs of UTI origin in Bangladesh.

\section{Material and Methods}

Study design and study subjects: This study was designed to identify the ESBL positive pathogens from UTI patients. All the procedures including; sample collection, cultural, biochemical and molecular identifications, antibiotic susceptibility testing, phenotypical and genotypical identification of ESBL producers and phylogenetical analysis of ESBL positive isolates were performed by following the standard international protocols.

In total, 90 urine samples were collected from patients with an age range of $>1$-above 60 years, who had clinical symptoms of UTI from two hospitals of Savar, Dhaka: Enam Medical College and Hospital (EMCH) and Gonoshastha Medical College and Hospital (GMCH). A total of 85 urine samples were collected from EMCH during June to August 2012 and 5 urine samples were collected from GMCH during July 2012 to September 2012. Five urine samples were collected from EMCH as negative control from UTI non infected persons.

Urine sample collection and sample preparation: UTI patients delivered their urine samples into the respective hospital laboratory according to their prescription. Most urine specimens were obtained from adult patients via the clean-catch midstream technique. ${ }^{22}$ Early morning urine was preferred. The samples refrigerated at $4^{\circ} \mathrm{C}$ until processing. A list of patient's information such as name, age, sex etc was collected from hospital record book. UTI samples from EMCH and GMCH were designated as $\mathrm{E}$ and $\mathrm{G}$, respectively followed by isolate number (ex: E1, G1). In each study, urine specimens were plated for microbial growth within 2 hours after collection. All the further test methods including cultural, molecular and bioinformatics were performed at Microbial Genetics and Bioinformatics Laboratory in Department of Microbiology, University of Dhaka, Bangladesh.

Isolation and Identification: Cultural and biochemical tests were performed to isolate bacterial strains from urine samples. The undiluted samples were spread onto Nutrient Agar (NA) and MacConkey Agar (MA) (Oxoid Ltd., Hampshire, 
UK) plates and incubated at $37^{\circ} \mathrm{C}$ for 24 hours. Control urine samples from healthy adult were also inoculated onto both NA and MA plates.

A series of standard biochemical tests including Kliglar Iron Agar (KIA) test, Indole test, Methyl red test, Vogges Proskaur test, Citrate test were performed to identify the bacteria of interest. ${ }^{23}$

Phenotypic Detection of ESBL-Double Disk Diffusion Synergy Test (DDST): DDST was performed to determine the phenotypic ESBL production of all 75 isolates from urine samples of UTI patients. ${ }^{24}$ The discs used in this study included ceftazidime (CAZ) $30 \mu \mathrm{g}$, ceftriaxone (CRO) $30 \mu \mathrm{g}$, cefotaxime (CTX) $30 \mu \mathrm{g}$, amoxycillin/clavulanic acid (AM/CLA) $30 \mu \mathrm{g}$ including $10 \mu \mathrm{g}$ CLA and aztreonam (AZT) $30 \mu \mathrm{g}$. The turbidity of test inoculums was matched to 0.5 Optical Density (OD) and was spread on Muller-Hinton Agar (MHA) (Oxoid, UK) using a sterile cotton swab. An AM/CLA $(20 \mu \mathrm{g}-10 \mu \mathrm{g})$ disc was placed on the center of the plate as a disc of augmenting. Then discs of CAZ $(30 \mu \mathrm{g})$, CRO $(30 \mu \mathrm{g})$, CTX $(30 \mu \mathrm{g})$ and AZT $(30 \mu \mathrm{g})$ were kept around it in such a way that each disc was at distance ranging between 15 and $20 \mathrm{~mm}$ from the augmenting disc (center to center). After 24 hours of incubation at $37^{\circ} \mathrm{C}$, band formation between the central AM/CLA disc and any other disc was considered ESBL positive.

Boronic acid disk potentiating test: Boronic Acid (BA) Disk Potentiating test requires a disk placement pattern to differentiate the ESBL and AmpC $\beta$ - lactamase producing Enterobacteriaceae. ${ }^{25}$ The test uses CTX, CTX plus CA, CTX plus boronic acid (CTX/BA) and CTX plus CA with BA, cefepime (FEP) and FEP with CA disk test, in a single plate with imipenem (IMP) at the center. Briefly, $5 \mu \mathrm{l}$ of the freshly prepared CA ( $2 \mathrm{~g} / 1$ of PBS at pH 6); was added to CTX (30 $\mu \mathrm{g})$, CAZ (30 $\mu \mathrm{g})$, and FEP $(30 \mu \mathrm{g})$ disks. Then $5 \mu \mathrm{l}$ of a 3 aminophenyl boronic acid (BA; Sigma Aldrich, India) stock solution ( $60 \mathrm{~g} / \mathrm{l}$ of DMSO) was added to CTX and CAZ disks with or without CA and also to the FEP disk. The final concentration of BA and CA on the disks was $300 \mu \mathrm{g}$ and $10 \mu \mathrm{g}$, respectively. The disks were allowed to dry for $60 \mathrm{~min}$ and used immediately. A lawn of test organism was made on the MHA after adjusting the inoculum to 0.5 McFarland unit and incubated at $35^{\circ} \mathrm{C}$ for $18-24$ hours in ambient air. This individual test can differentiate among five different groups such as: (a) Pure ESBL (b) Pure AmpC producers (c) Pure AmpC-ESBL producers (d) Inducible AmpC producers and (e) Isolates harboring no enzymes.

Antibiotic susceptibility testing: All phenotypic ESBL isolates were detected in vitro by using the standardized agar-disc-diffusion method of KirbeyBauer. ${ }^{26}$ Fourteen different commercially available antibiotic discs (Oxoid, Basingstoke, United Kingdom) belonging to 9 individual groups of antibiotics and MHA plate were used for the test. The zone diameter for individual antimicrobial agents was measured and then translated into sensitive, moderate or resistant categories according to the interpretation of CLSI. According to the guideline of European Centre for Disease Prevention and Control (ECDC) and the Centers for Disease Control and Prevention (CDC), MDR pathogens were selected for further analysis. ${ }^{13}$

PCR Detection of ESBL Specific Genes and Sequence Analysis: All the phenotypically ESBL positive MDR isolates were selected for detailed molecular analysis. Total DNA from the isolates were prepared by boiled DNA method to use as template DNA for PCR. PCRs using primers specific for antibiotic resistance genes such as bla $a_{\mathrm{TEM}}$, and $b l a_{\text {СTX-M }}$ were carried out using a thermal cycler (Biometra, Germany). The PCR reactions were carried out according to the published protocol for $b l a_{\mathrm{TEM}}$ and $b l a_{\mathrm{CTX}}{ }^{27,28}$ Purified PCR products were sequenced on an ABI sequencer (ABI Prism 3130 Genetic Analyzer, USA). Full length sequences (858 bp for bla $a_{\mathrm{TEM}}$, and 593 bp for bla $a_{\mathrm{CTX}}$ M) were assembled into full length sequence using the SeqMan Genome Assembler (DNA star, USA) and compared to the GenBank database of the National Center for Biotechnology Information (NCBI) (http://www.ncbi.nlm.nih.gov/GenBank) by means of the Basic Local Alignment Search Tool (BLAST) to identify close phylogenetic relatives. 
Multiple sequence alignment of the retrieved reference sequences from NCBI was performed with the ClustalW software and was exported to the Molecular Evolutionary Genetics Analysis (MEGA) program for phylogenetic tree construction using the Neighbor joining algorithm selecting 1000 bootstrap replication. ${ }^{29,30}$

Plasmid DNA Analysis: Plasmid DNA of ESBL specific gene positive isolates was extracted using Wizard ${ }^{\circledR}$ PlusMinipreps plasmid DNA Purification kit (Promega, USA). Isolated plasmid DNA was separated in $0.8 \%$ agarose gel (ethidium bromide added) in a Tris-Acetate- EDTA (TAE) buffer and photograph was taken using GelDoc (AlphaImager, USA). Escherichia coli $\mathrm{V}_{517}$ plasmid was used as control and marker plasmid DNA.

$16 S$ rRNA Gene Sequencing and Identification: The 16S rRNA gene of representative ESBL isolates belonging to each morphological group was amplified using primers $27 \mathrm{~F}$ and $1492 \mathrm{R}^{31}$ The purified products were further used for sequencing and phylogenetic analysis as same as the protocol used in case of ESBL genes.

Ethical clearance was obtained from the Ethical Committee of Faculty of Biological Science, University of Dhaka, Bangladesh.

\section{Results}

Age and Sex Distribution of Patients: Among 90 UTI patients, $56 \%$ (53 out of 90) were female and $46 \%$ (36 out of 90) were male (figure 1 a).

From EMCH, 46 Urine samples were collected from female and 39 samples were collected from male patients whereas from $\mathrm{GMCH}, 4$ samples were collected from female and 1 from male patient. The patients were additionally categorized into four different age groups; as such, >1 to 20, 21 to 40, 41 to 60 and 61 to $>80$. Among these age groups 21 to 40 age group was more prevalent in causing UTI among patients (figure $1 \mathrm{~b}$ ).

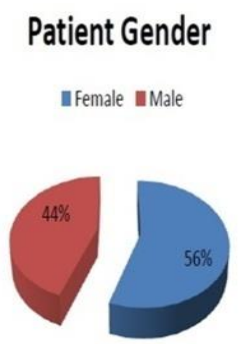

(a)

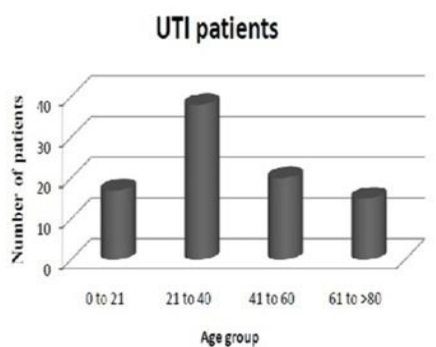

(b)
Figure 1: UTI patient's history from both hospitals- EMCH and GMCH (a) Diagrammatic presentation of patient's gender; (b) Age group distribution of UTI among patients.

Isolation and identification of microorganisms: Each of the urine samples showed single colony type in case of both NA and MA media. Among 85 samples from $\mathrm{EMCH}, 70$ were culture positive on NA plates whereas all of the 5 urine samples of GMCH were culture positive on NA. The 5 control samples showed no growth on both NA and MA plates. The isolates were gram negatives and were classified into four morphogroups according to the colony characteristics on MA media: i) moderate pink with dark ring ii) light pink with glossy texture iii. pink, dry with small shape and iv. pale, circular and glossy texture (Supplementary figure 1). Isolates of four morphogroups were presumptively identified through standard biochemical tests. According to the biochemical results of 75 isolates of UTI origin from MA plates, $41 \%$ (31 out of 75) were Escherichia spp., 26\% (20 out of 75) were Enterobacter spp. and $21 \%$ (16 out of 75 ) were Klebsiella spp. . 10\% (8 out of 75) of all isolates were non enterobacter which are primarily identified as Pseudomonas spp.

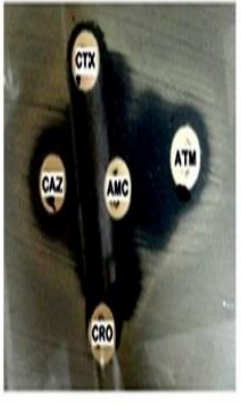

(A)

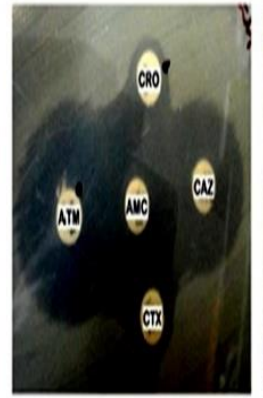

(B)

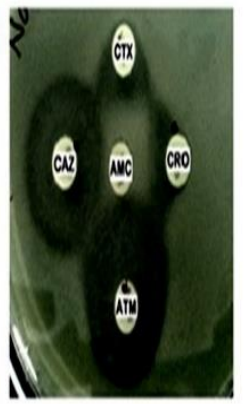

(C)
Figure 2: Distinguished patterns of Double Disk Diffusion Test (DDST) of ESBL positive UTI isolates. Representative isolates are: (A) E81; (B) G5; (C) E57. (CTX-Cefotaxime, CAZ- Ceftazidime, CRO- Ceftriaxone, AZTAzithromycine, AM/CLA- Amoxycillin/Clavulanic acid) 
Isolation of ESBL producing organisms: A total of 75 isolates from 75 culture positive UTI samples from NA and MA plates, were subjected to DDST disk diffusion test. Among them, 31 isolates showed phenotypic ESBL production pattern (figure 2, table I).

ESBL producing isolates showed three patterns. as well: (a) isolates resistant to CAZ, CRO, CTX, and AZT showing tunneling of zone of inhibition towards AM/CLA (b) isolates resistant to CTX and CRO tunneled towards AM/CLA and (c) isolates resistant to CTX, CRO, and AM/CLA. (figure: 2, table I)

BA Disk Potentiating Test was done on randomly selected 25 isolates from four morphogroups of ESBL positive organisms that showed positive result in DDST (table I). According to BA disk potentiating assay, isolates have been categorized into five different groups including pure ESBL and pure AmpC producers.

Among 25 isolates 9 isolates were selected as pure ESBL producing (E30, E36, E37, E56, E59, E61, E79, G4, G5); 2 isolates were pure AmpC producing (E16, G3); 5 isolates were AmpC- ESBL producers (E40, E41, E42, E57, E60); 3 isolates (E13, E64, G2) were selected as Inducible AmpC-producing isolates showing the inhibition of cephalosporin blunting after the addition of BA and another 6 isolates were considered as isolates without harboring any type of enzymes as did not show any characteristic tunneling with augmenting zone (E14, E17, E62, E80, E81, E83).

Table I: Four morphological groups of ESBL isolates showing variations in their antibiotic resistance pattern and genotyping of $\beta$-lactamases genes (bla TEM $_{\text {and }}$ bla $a_{\text {CTX-M). }}$

\begin{tabular}{|c|c|c|c|c|c|}
\hline $\begin{array}{c}\text { Source } \\
\text { morphological } \\
\text { groups of UTI } \\
\text { ESBLs } \\
\end{array}$ & Isolate ID & Antibiotic resistance pattern & $\begin{array}{c}\text { bla }_{\mathrm{tem}} \\
(\mathbf{8 5 3} \mathrm{bp})\end{array}$ & $\begin{array}{c}b_{\text {ctx- }} \\
\text { M } \\
(593 \\
\text { bp) } \\
\end{array}$ & $\begin{array}{l}\text { Phylogenetically } \\
\text { related organisms }\end{array}$ \\
\hline \multirow{13}{*}{$\begin{array}{c}\text { Gr. I; } \\
\text { Moderate, pink } \\
\text { surrounding } \\
\text { dark ring, } \\
\text { circular, entire, } \\
\text { matt, flat }\end{array}$} & E8 & CIP, C, N, TET, CFM, CTX, CRO, CAZ, AZT & - & + & \multirow{13}{*}{$\begin{array}{c}\text { G4, G5, E19, E61, E36, } \\
\text { E40, G3: } \\
\text { Escherichia } \text { sp. }\end{array}$} \\
\hline & E10 & CIP, N, CFM, CTX, CRO, CAZ, AZT & - & + & \\
\hline & E14 & CIP,AZT, TET, CFM, CTX, CRO, CAZ, AZT & - & + & \\
\hline & E30 & AM, CIP, C, IMP,AZM, LEV, CTX, CRO, CAZ, AZT & - & - & \\
\hline & E36 & AM, AMP, CIP, AZT, C, N, TET, CFM, IMP, AZM, LEV, CTX, CRO, CAZ & + & + & \\
\hline & E19 & AMP, CIP, AZT, CFM, AZM, LEV, CTX, CRO & + & + & \\
\hline & $\mathrm{E} 40$ & AM, AMP, CIP, AZT, C, N, TET, CFM, IMP, AZM, LEV, CTX, CRO, CAZ & + & + & \\
\hline & E61 & AM, AMP, CIP, AZT, C, N, TET, CFM, IMP, AZM, LEV, CTX, CRO, CAZ & + & + & \\
\hline & G4 & CIP, C, N, TET, CFM, CTX, CRO & + & + & \\
\hline & G5 & $\mathrm{AM}, \mathrm{CIP}, \mathrm{C}, \mathrm{N}, \mathrm{TET}, \mathrm{CFM}, \mathrm{CTX}, \mathrm{CRO}$ & + & + & \\
\hline & E60 & AMP, CIP, N, TET, AZM & + & + & \\
\hline & $\mathrm{G} 2$ & AM, AMP, CIP, N, TET, CFM, AZM, CTX, CRO, CAZ, AZT & - & - & \\
\hline & G3 & AM, AMP, CIP, C, N, TET, CFM, CTX, CRO, CAZ, AZT & - & + & \\
\hline \multirow{4}{*}{$\begin{array}{c}\text { Gr. II; } \\
\text { Moderate, light } \\
\text { pink, circular, } \\
\text { convex, glossy }\end{array}$} & E37 & AM, AMP, TET, CFM, CTX, CRO, CAZ, AZT & + & + & \multirow{4}{*}{$\begin{array}{c}\text { E37 } \\
\text { Klebsiella sp. }\end{array}$} \\
\hline & E42 & AM, AMP, CIP, C, N, TET, CFM, IMP, CTX, CRO & + & + & \\
\hline & E64 & AM, AMP, CIP, AZT, C, N, TET, CFM, IMP, AZM, LEV, CTX, CRO, CAZ & + & + & \\
\hline & E80 & AM, AMP, CIP, C, CFM, CTX, CRO, CAZ, AZT & - & - & \\
\hline \multirow{11}{*}{$\begin{array}{l}\text { Gr. III; Small, } \\
\text { pink, oval, } \\
\text { raised, dry }\end{array}$} & E9 & C, N, TET, CFM, AZT, CTX, CRO & - & + & \multirow{11}{*}{$\begin{array}{c}\text { E78 } \\
\text { Enterobacter } \\
\text { hormacchei }\end{array}$} \\
\hline & E13 & AM, CIP, C, CFM, TET, N, LEV, CTX, CRO & - & + & \\
\hline & E16 & CIP, CFM, TET, AZM, CTX, CRO & + & - & \\
\hline & E17 & CIP, AMP, LEV, AZM, CFM, CTX, CRO & - & - & \\
\hline & E41 & AM, CIP, AMP, IMP, CFM, CTX, CRO, CAZ, AZT & + & + & \\
\hline & E62 & AM,CIP, AMP, N, TET, CTX, CRO & - & - & \\
\hline & E74 & AM, CIP, N, IMP, TET, AMP, CFM, CTX, CRO & - & - & \\
\hline & E78 & AM, CIP, N, IMP, TET, CFM, CTX, CRO & - & - & \\
\hline & E83 & CIP, AMP, TET, CFM, CTX, CRO & - & - & \\
\hline & E56 & AMP, CIP, CFM, , CTX, CRO & + & + & \\
\hline & E59 & AMP, CIP, AZT, CFM, TET, CTX, CRO & + & + & \\
\hline \multirow{3}{*}{$\begin{array}{l}\text { Gr. IV;Small, } \\
\text { pale, irregular, } \\
\text { glossy }\end{array}$} & E57 & AM, CIP, AZM, C, N, IMP, TET, AMP, AZT, LEV, CFM, CTX, CRO & + & + & \multirow{3}{*}{$\begin{array}{c}\text { E57 } \\
\text { Pseudomonas } \\
\text { aerugenosa }\end{array}$} \\
\hline & E79 & $\mathrm{AM}, \mathrm{CIP}, \mathrm{TET}, \mathrm{CFM}, \mathrm{CTX}, \mathrm{CRO}, \mathrm{CAZ}, \mathrm{AZT}$ & - & - & \\
\hline & E81 & AM, CIP, C, TET, AMP, CFM, CTX, CRO, CAZ, AZT & + & - & \\
\hline
\end{tabular}

a. Amoxycillin (AM), Ampicillin (AMP), Azithromycin (AZM), Aztreonam (AZT), Cirpofloxacin (CIP), Levofloxacin (LEV), Chloramphenicle (C), Cefotaxime (CTX), Ceftazidime (CAZ), Ceftriaxone (CRO), Cefixime (CFM), Imipenem (IMP), Nitrofuran (N), Tetracycline (TET)

b. *bold isolates were selected for boronic acid disk potentiation assay 


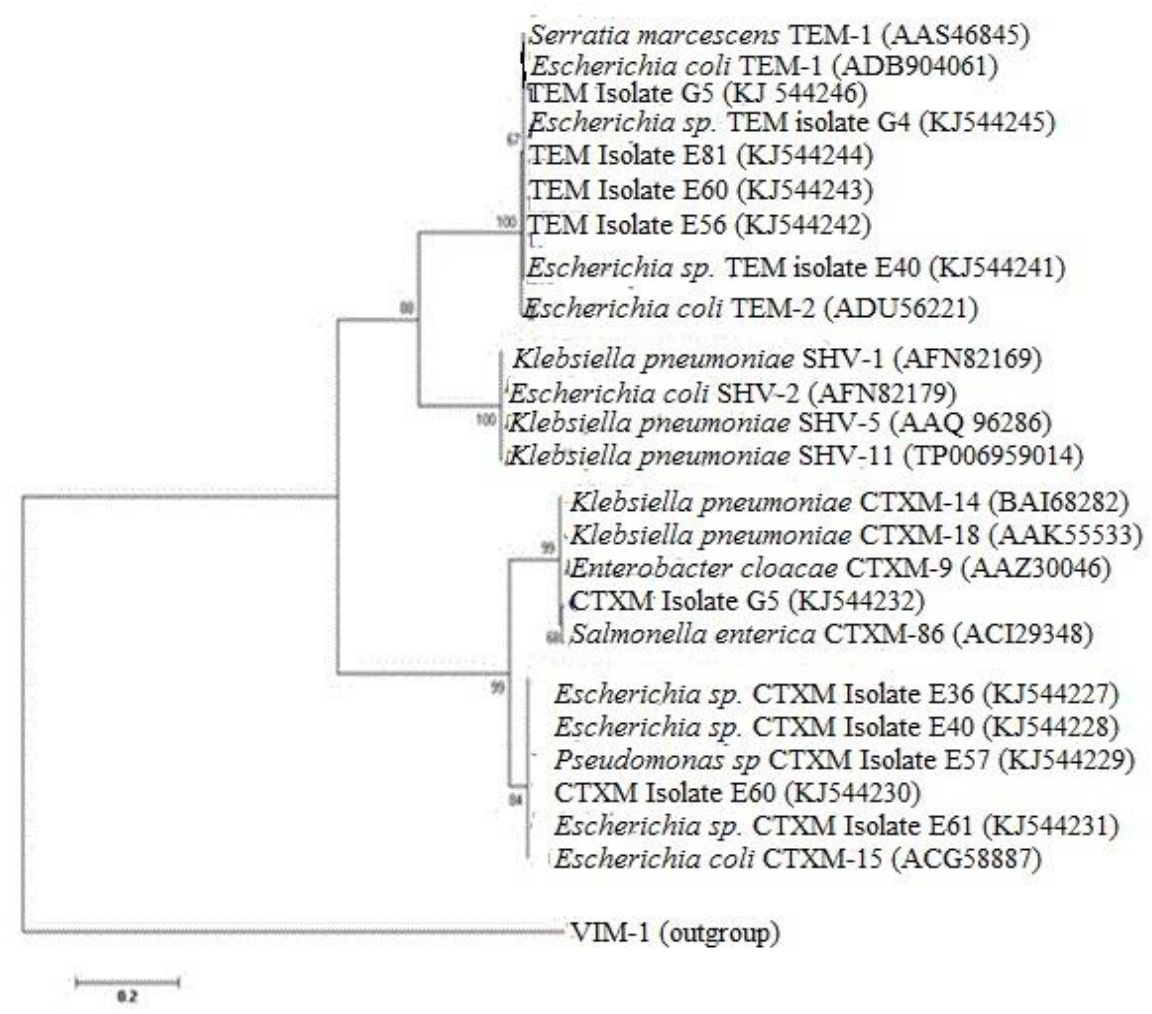

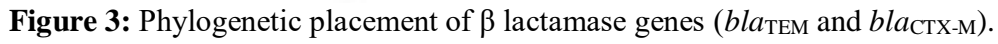

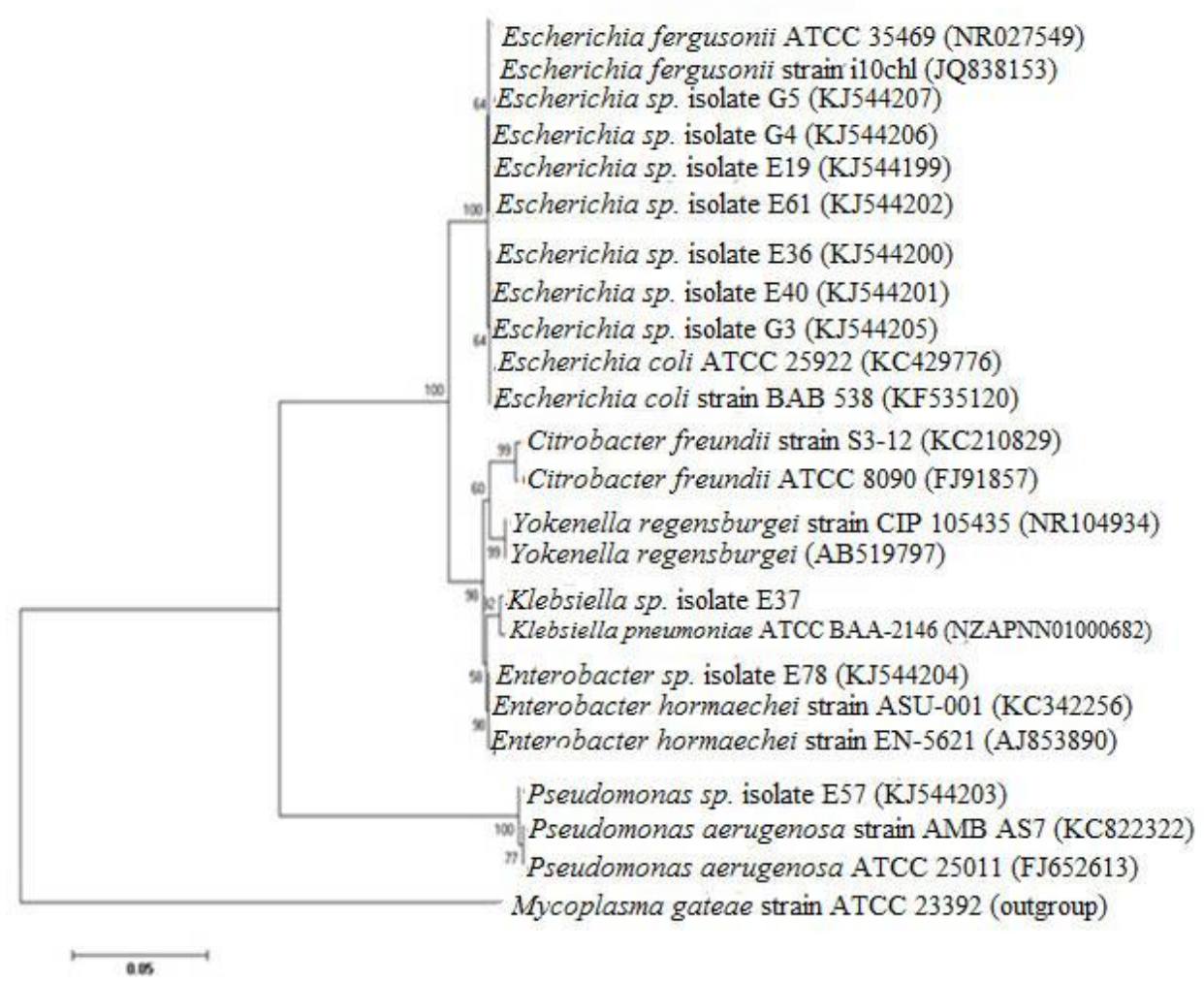

Figure 4: Phylogenetic placement of 16S rRNA gene sequences of ESBL positive isolates. 
Antibiotic susceptibility pattern of ESBL morphological groups: Within the morphogroups of UTI isolates, Group I contain 13 ESBL positive isolates among which 12 were Ciprofloxacin (CIP), whereas most of the isolates were resistant to Amoxycillin (AM) and Cefixime (CFM). Many isolates were resistant to Tetracycline (TET) and Nitrofuran (N). Group II contained 4 DDST positive isolates (E19, E61, E64, E80) (table I) and showed resistance to Ampicillin (AMP), CIP and CFM. Among the four isolates, 3 were resistant to $\mathrm{AM}$ and Chloramphenicle (C) except E19. Furthermore, except isolate E80, all others were resistant to Levofloxacin (LEV). All four of them were resistant to Aztreonam (AZT). Group III included 11 isolates and showed resistant to CIP, CFM and AM. Group IV contain 3 isolates, (E57, E79, and E81), all of them were resistant to CIP, AM, Cefotaxime (CTX), CRO, CFM, AZT, and TET (table I). All the isolates have shown resistance to at least 5 types of antibiotic to more than 10 types of antibiotic. More than $90 \%$ isolates showed resistance against CTX, CRO, CIP and CFM. Azithromycin, IMP and LEV showed to be comparatively better antibiotic against the uropathogens.

Analysis of ESBL genes: The prevalent ESBL genotype was $b a_{\text {СТX-M }}$ type, $65 \%$ (20/31) of among the total isolates (table I). The frequency of bla $a_{\mathrm{TEM}}$ genotype was $52 \%(16 / 31) ; 35 \%$ of the isolates

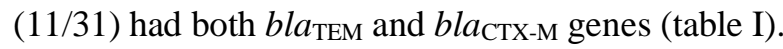

Sequencing and homology search using Gen Bank database of the ESBL specific $b l a_{\mathrm{TEM}}$ and $b l a_{\mathrm{CTX}-\mathrm{M}}$ genes showed that all TEM-1 positive isolates were 100\% similar to TEM1 enzyme of Escherichia coli TEM-1 (ADB904061). All CTX positive isolates except G5 (UTI) showed 100\% similarity with Escherichia coli CTX-M-15 (ACG58887). Only one isolate G5 of UTI sample showed 100\% similarity with CTX-M-9 enzyme of Enterobacter cloacae (AAZ30046) (figure III). Accession number of NCBI submitted ESBL-TEM positive isolates are KJ544241-46 and ESBL- CTX positive isolates are KJ544227-32.

Plasmid profiling: Among the 31 ESBL positive MDR isolates, 7 of them were plasmid free. They included: E30, E56, E60 (morphogroup I), E19 (morphogroup II), E83 (morphogroup III), E57 and E81 (morphogroup IV) (Supplementary table I, Supplementary figure 1). Large plasmids above the chromosomal range were found in the isolates E37 and E40.The rest of the isolates showed multiple plasmid bands ranging from around $6 \mathrm{~kb}$ to less than $1 \mathrm{~kb}$. Most of the plasmids belong in the size range of $3 \mathrm{~kb}$ to $4 \mathrm{~kb}$.

$16 S$ rRNA Gene Identification of ESBL Positive Isolates: $16 \mathrm{~S}$ rRNA gene sequences of isolates G4, G5, E19, E61, E36, E40 and G3 of morphogroup I was closely related to Escherichia coli whereas isolates E37 from group II were clustered with Klebsiella sp. E78 from group III and E57 from group IV were closely related to Enterobacter sp. and Pseudomonas sp., respectively (figure 4). Accession number of NCBI submitted 16s rRNA gene sequences of UTI isolates are KJ544199-207.

\section{Discussion}

Gram-negative bacilli especially $E$. coli and $K$. pneumonia carrying ESBL enzyme are considered as serious pathogens in patients of UTI worldwide. ${ }^{32}$ Trimethoprim/sulfamethoxazole, ciprofloxacin, cephalosporins, semi-synthetic penicillin with or without inhibitors, nitrofurantoin and fosfomycin are the most commonly used antibacterial drugs in the treatment of community-acquired UTIs. ${ }^{33}$ The extensive use of antibiotics and switching to newer antibiotics to treat UTI patients is alarmingly increasing, especially in countries like Bangladesh. The present study is an endeavor on the isolation and characterization of MDR- ESBL producing Gram negative bacteria, especially Enterobacteriaceae from urine samples of UTI patients in a specific area of Dhaka region in Bangladesh.

In this study, total 90 urine samples from UTI patients were collected from two different hospitals, EMCH and GMCH located in Savar, Dhaka of which majority of the patients were female $(56 \%)$ with adult age group (21-40 years). This observation was similar to other reports in India and Pakistan respectively. ${ }^{35-36}$ 
MDR is a major problem in the management of UTI patients. $^{26}$ Since MDR- ESBL producing Enterobacteriaceae was the primary focus of the study, the isolates were confirmed through inoculating onto MA plate.

Among the isolates, E coli is more prevalent (41\%) than other organisms which are in agreement with findings done at Mymensingh Medical College during time period from July 2007 to June 2008. ${ }^{37}$ Again, Klebsiella spp. was found to be $21 \%$ and other Enterobacter spp. was $26 \%$ among total isolates. Pseudomonas spp. was about $10 \%$ among total isolated organisms.

Gram negative isolates of UTI origin were selected for detection of ESBL production by conventional DDST and BA Disk Potentiating Test to differentiate ESBL and AmpC- ESBLs. With DDST, $36 \%$ (31 among 85) of the isolates were ESBL producers. Among ESBL producers, highest percentage were among Escherichia spp. (41\%, 13 out of 31), then $35 \%$ ESBL producers were among Enterobacter spp. and then $13 \%$ of the ESBL producing isolates were Klebsiella spp. Among 31 ESBL producers 3 isolates were screened as nonenterobacteriaceae Pseudomonas spp. (10\%).

The dominant genotype of ESBL among the two ESBL coding genes (bla $a_{\mathrm{TEM}}$ and $b l a_{\mathrm{CTX}-\mathrm{M}}$ ), were detected to be CTX-M type (65\%) followed by TEM genotype (52\%) (table I). Phylogenetically, it was observed that TEM-1 and CTX-M-15 types were predominant in Bangladesh samples (figure 3). In India, CTX-M-15 genotype was also reported to be dominant within E. coli $(75 \%)$ and Klebsiella spp. $(73 \%) .{ }^{38}$ The dominance or co-dominance of CTX$\mathrm{M}$ gene within the isolates may be due to overuse of $\mathrm{CRO}$ or due to fecal carriage and transfer gene by horizontal transmission. ${ }^{38}$

Among the total $31 \mathrm{ESBL}$ positive isolates, 25 of them were randomly selected from 3 DDST patterns which were subjected to BA potentiating test. According to their disk layout pattern in BA potentiating test, 9 of them were detected as pure ESBL and 2 isolates showed result as pure AmpC producers whereas 5 of them were AmpC-ESBL producing organisms. 3 of them were inducible
AmpC-producing isolate showing the inhibition of cephalosporin blunting after the addition of BA and 6 isolates do not harbor any type of enzyme.

MDR pattern of the ESBL isolates were determined with fourteen (14) different antibiotics of nine (9) different groups. Among these, 31 isolate (Approximately 100\%) (27 from EMCH and 4 from GMCH) showed MDR properties. Highest percentage of resistance was observed against CTX (96\%), whereas lowest percentage of resistance was found against LEV (29\%); $93 \%$ of the isolates were resistant to CIP, 74\% isolates were resistant to AMP and AZT and 32\% of them were even IMP resistant. Among non enterobacteriaceae isolates resistance pattern was as high as Enterobacteriaceae. Among total 3 ESBL positive Pseudomonas isolates 1 were resistant to IMP and all of the isolates were also resistant to AMP, TET and CIP antibiotics.

Noteworthy to mention that, a study was carried out by a group from our laboratory to determine the most frequently used antibiotics to UTI patients in the hospitals. It was observed that most frequently used antibiotics in the DMCH (Dhaka Medical College Hospital), CMCH (Chittagong Medical College Hospital) and EMCH were cephalosporin and fluoroquinolone groups of antibiotics followed by penicillin, gentamycin and TET. Among these, CFM within the cephalosporin and CIP within the fluoroquinolone groups were mostly used.

The high prevalence of ESBL plus AmpC coproduction indicates the inappropriate use of extended spectrum cephalosporins. Antibiotic coresistance was high among ESBL, AmpC and coproducers. (table I) This may be due to the fact that plasmids carrying these enzymes may carry coresistance genes for other antibiotics. ${ }^{39}$

In the present study, most of the ESBL positive isolates harbor multiple numbers of plasmids, which strikes to the point that the multidrug resistant properties of the isolates might be plasmid borne (table I). Seven among 31 isolates, do not harbor plasmid, still they were found to be ESBL producers both phenotypically and genotypically, which leads to the conclusion that their ESBL properties might be chromosome borne. ${ }^{40}$ 
A mixed type of drug resistance mechanisms seem to operate in the isolates from UTI patients. So, the detection of the co-production of ESBL and AmpC is essential for effective antimicrobial therapy and enhanced infection control. Inhibitor based method such as BA disc potentiating test can be followed beside conventional DDST method to detect the pathogens producing ESBL and AmpC $\beta$-lactamase.

\section{Conclusion}

This study concludes that i) The UTI patients of our country harbor a large number of MDR Gram negative bacteria, among which the predominant species are Escherichia spp., Klebsiella spp., Enterobacter spp. and Pseudomonas spp. etc., ii) The MDR isolates frequently produce $\beta$-lactamase iii) ESBL properties of the isolates may be plasmid or chromosomal borne and iv) CTXM classes of $\beta$ lactamase gene is prevalent within the UTI Gram negative isolates.

\section{Acknowledgement}

The work was conducted with a from the grants provided by University Grants Commission (UGC), and fellowship provided by Ministry of Science and Technology (MOST), Bangladesh. Authors also like to acknowledge the help from Higher Education Quality Enhancement Project (HEQEP) for equipment facility to complete this work. National Science and Technology (NST) fellowship also helped to complete the work.

Conflict of interest: The authors declares no conflict of interest.

\section{References}

1. Rahman MM, Haq JA, Hossain MA, Sultana R, Islam F, and Islam AS, Prevalence of extended-spectrum $\beta$ lactamase-producing Escherichia coli and Klebsiella pneumoniae in an urban hospital in Dhaka, Bangladesh. International Journal of Antimicrobial agents. 2004; 24:508-510.

2. Adnan N, Sultana M, Islam OK, Nandi SP, and Hossain MA. Characterization of Ciprofloxacin resistant Extended Spectrum $\beta$-Lactamase (ESBL) producing Escherichia spp. from clinical waste water in
Bangladesh. Advances in Bioscience and Biotechnology. 2013; 4:15-23.

3. Nandi SP, Sultana M, and Hossain MA. Prevalence and characterization of multidrug-resistant zoonotic Enterobacter spp. in poultry of Bangladesh. Foodborne Pathogens and Disease. 2013; 10:420-427.

4. Sultana M, Bilkis R, Diba F, and Hossain MA. Predominance of Multidrug Resistant Zoonotic Salmonella Enteritidis Genotypes in Poultry of Bangladesh. The Journal of Poultry Science. 2014; 51:424-434.

5. Bradford PA. Extended-spectrum $\beta$-lactamases in the 21st century: characterization, epidemiology, and detection of this important resistance threat. Clinical Microbiology Reviews. 2001; 14:933-951.

6. Paterson DL. Resistance in gram-negative bacteria: Enterobacteriaceae. The American Journal of Medicine. 2006; 119:S20-S28.

7. Perez F, Endimiani A, Hujer KM, and Bonomo RA. The continuing challenge of ESBLs. Current Opinion in Pharmacology. 2007; 7:459-469.

8. Picozzi SC, Casellato S, Rossini M, Tejada M, Costa E, and Carmignani L. Extended-spectrum beta-lactamasepositive Escherichia coli causing complicated upper urinary tract infection: Urologist should act in time. Urology Annals. 2014; 6:107.

9. Manges AR, Tabor H, Tellis P, Vincent C, and Tellier PP. Endemic and epidemic lineages of Escherichia coli that cause urinary tract infections. Emerging Infectious Diseases. 2008; 14:1575.

10. Ejrnæs K. Bacterial characteristics of importance for recurrent urinary tract infections caused by Escherichia coli. Dan Med Bull. 2011; 58:B4187.

11. Hsueh PR, Hoban DJ, Carmeli Y, Chen SY, Desikan S, Alejandria $\mathrm{M}$, et al., Consensus review of the epidemiology and appropriate antimicrobial therapy of complicated urinary tract infections in Asia-Pacific region. Journal of Infection. 2011; 63:114-123.

12. Tankhiwale SS, Jalgaonkar SV, Ahamad S, and Hassani U. Evaluation of extended spectrum beta lactamase in urinary isolates. Indian J Med Res. 2004; 120:553-6.

13. Magiorakos AP, Srinivasan A, Carey RB, Carmeli Y, Falagas ME, Giske CG, Harbarth S, Hindler JF, Kahlmeter G, Olsson-Liljequist B, Paterson DL, Rice LB, Stelling J, Struelens MJ, Vatopoulos A, Weber JT and Monnet DL. Multidrug-resistant, extensively drugresistant and pandrug-resistant bacteria: an international expert proposal for interim standard definitions for 
acquired resistance. Clin Microbiol Infect. 2012; 18:268-281.

14. Ho PL, Wong RC, Yip KS, Loke SL, Leung MS, Mak GC, et al., Antimicrobial resistance in Escherichia coli outpatient urinary isolates from women: emerging multidrug resistance phenotypes. Diagnostic Microbiology and Infectious Disease. 2007; 59:439-445.

15. Mathai E, Grape M, and Kronvall G. Integrons and multidrug resistance among Escherichia coli causing community-acquired urinary tract infection in southern India. Apmis. 2004; 112:159-164.

16. Santo E, Salvador MM, and Marin JM. Multidrugresistant urinary tract isolates of Escherichia coli from Ribeirão Preto, São Paulo, Brazil. Brazilian Journal of Infectious Diseases. 2007; 11:575-578.

17. Warren JW, Abrutyn E, Hebel JR, Johnson JR, Schaeffer AJ, and Stamm WE. Guidelines for antimicrobial treatment of uncomplicated acute bacterial cystitis and acute pyelonephritis in women. Clinical Infectious Diseases. 1999; 29:745-759.

18. Mehrgan H, and Rahbar M. Prevalence of extendedspectrum $\beta$-lactamase-producing Escherichia coli in a tertiary care hospital in Tehran, Iran. International Journal of Antimicrobial Agents. 2008; 31:147-151.

19. Lina TT, Khajanchi BK, Azmi IJ, Islam MA, Mahmood B, Akter M, et al., Phenotypic and Molecular Characterization of Extended-Spectrum BetaLactamase-Producing Escherichia coli in Bangladesh. PLOS one. 2014; 9:e108735.

20. Masud MR, Afroz H, and Fakruddin M. Prevalence of extended-spectrum $\beta$-lactamase positive bacteria in radiologically positive urinary tract infection. SpringerPlus. 2014; 3:216.

21. Khan SA, Feroz F, Noor R. Study of extended-spectrum $\beta$-lactamase-producing bacteria from urinary tract infections in Bangladesh. Tzu Chi Medical Journal. 2013; 25: 39e42.

22. Shigemura K, Tanaka K, Okada H, Nakano Y, Kinoshita S, Gotoh A, et al., Pathogen occurrence and antimicrobial susceptibility of urinary tract infection cases during a 20-year period (1983-2002) at a single institution in Japan. Japanese Journal of Infectious Diseases. 2005; 58:303.

23. Cappuccino JG, and Sherman N. Microbiology: a laboratory manual. Vol. 9. 2008: Pearson/Benjamin Cummings.

24. Jarlier V, Nicolas MH, Fournier G, and Philippon A. Extended broad-spectrum $\beta$-lactamases conferring transferable resistance to newer $\beta$-lactam agents in
Enterobacteriaceae: hospital prevalence and susceptibility patterns. Review of Infectious Diseases. 1988; 10:867-878.

25. Shoorashetty R, Nagarathnamma $T$, and Prathibha $J$. Comparison of the boronic acid disk potentiation test and cefepime-clavulanic acid method for the detection of ESBL among AmpC-producing Enterobacteriaceae. Indian Journal of Medical Microbiology. 2011; 29:297.

26. Akram M, Shahid M, and Khan AU. Etiology and antibiotic resistance patterns of community-acquired urinary tract infections in JNMC Hospital Aligarh, India. Annals of clinical microbiology and antimicrobials. 2007; 6:4.

27. Arlet G, Brami G, Decre D, Flippo A, Gaillot O, Lagrange $\mathrm{P}$, et al., Molecular characterisation by PCRrestriction fragment length polymorphism of TEM $\beta$ lactamases. FEMS Microbiology Letters. 1995; 134:203-208.

28. Pagani L, Dell'Amico E, Migliavacca R, D'Andrea MM, Giacobone E, Amicosante G, et al., Multiple CTX-Mtype extended-spectrum $\beta$-lactamases in nosocomial isolates of Enterobacteriaceae from a hospital in northern Italy. Journal of Clinical Microbiology. 2003; 41: 4264-4269.

29. Larkin MA, Blackshields G, Brown N, Chenna R, McGettigan PA, McWilliam H, et al., Clustal W and Clustal X version 2.0. Bioinformatics. 2007; 23:29472948.

30. Tamura K, Dudley J, Nei M, and Kumar S, MEGA4: molecular evolutionary genetics analysis (MEGA) software version 4.0. Molecular Biology and Evolution, 2007; 24:1596-1599.

31. Milinovich G, Trott D, Burrell P, Van Eps A, Thoefner $\mathrm{M}$, Blackall L, et al., Changes in equine hindgut bacterial populations during oligofructose-induced laminitis. Environmental Microbiology. 2006; 8:885898.

32. Alipourfard I, and Nili NY. Antibiogram of Extended Spectrum Beta-lactamase (ESBL) producing Escherichia coli and Klebsiella pneumoniae isolated from Hospital Samples. Bangladesh Journal of Medical Microbiology. 2010; 4:32-36.

33. Hryniewicz K, Szczypa K, Sulikowska A, Jankowski K, Betlejewska K, and Hryniewicz W. Antibiotic susceptibility of bacterial strains isolated from urinary tract infections in Poland. Journal of Antimicrobial Chemotherapy. 2001; 47:773-780.

34. Rahman MR, Rahim MA, Afroze SR, Afroz F, Haque HF, Mitra P, et al. Pattern of Bacterial Pathogens 
Causing Urinary Tract Infection and Their Antibiotic Sensitivity: A Tertiary Care Hospital Experience. Birdem Med J. 2015; 5:20-23.

35. Hasan AS, Nair D, Kaur J, Baweja G, Deb M, and Aggarwal P. Resistance patterns of urinary isolates in a tertiary Indian hospital. J Ayub Med Coll Abbottabad. 2007; 19:39-41.

36. Ullah F, Malik S, and Ahmed J. Antibiotic susceptibility pattern and ESBL prevalence in nosocomial Escherichia coli from urinary tract infections in Pakistan. African Journal of Biotechnology. 2009. 8.

37. Parvin US, Hossain M, Musa A, Mahamud C, Islam M, Haque N, et al., Pattern of aerobic bacteria with antimicrobial susceptibility causing community acquired urinary tract infection. Mymensingh Medical Journal: MMJ. 2009; 18:148-153.
38. Ensor V, Shahid M, Evans J, and Hawkey P. Occurrence, prevalence and genetic environment of CTX-M $\beta$-lactamases in Enterobacteriaceae from Indian hospitals. Journal of Antimicrobial Chemotherapy. 2006; 58:1260-1263.

39. Stamm WE, Counts GW, Running KR, Fihn S, Turck $\mathrm{M}$, and Holmes KK. Diagnosis of coliform infection in acutely dysuric women. New England Journal of Medicine. 1982; 307:463-468.

40. Szczepanowski R, Linke B, Krahn I, Gartemann KH, Gützkow T, Eichler W, et al., Detection of 140 clinically relevant antibiotic-resistance genes in the plasmid metagenome of wastewater treatment plant bacteria showing reduced susceptibility to selected antibiotics. Microbiology.2009;155:2306-2319. 